\title{
The effects of age on perceptual field dependence
}

\author{
JO ANN LEE and ROBERT H. POLLACK \\ University of Georgia, Athens, Georgia 30602
}

\begin{abstract}
The purpose of this study was to investigate age differences in problem solving situations that are affected by field dependence. The portable rod-and-frame test and two series of ambiguous figures were employed as measures of field dependence. These tests were administered to 12 females in each of the following age groups: 40s, 50s, and 60s. All subjects were moderately to well educated, healthy, and relatively active members of the community. All had at least 20/33 corrected or uncorrected vision. Neither age nor menopausal status nor hormonal level was found to be significant factors affecting performance.
\end{abstract}

Lee and Pollack (1978) have sought to discern the reason for the often reported deficit in problem solving ability that occurs during senescence (Arenberg, 1973; Axelrod \& Cohen, 1961; Baltes \& Labouvie, 1973; Basowitz \& Korchin, 1957; Clay, 1954; Friend \& Zubeck, 1958; Jerome, 1962; Welford, 1958, 1969; Wiersma \& Klausmeier, 1965; M. L. Young, 1966, 1971). The results they obtained suggest that a perceptual problem rather than a deficit in higher order processes could underlie the decline in cognitive performances with advanced age. The implementation of Witkin's standard 12-item embedded figures test (EFT; Witkin, Oltman, Raskin, \& Karp, 1971) by Lee and Pollack was an appropriate choice, since the test has proven to be a valid measure of intellectual ability as well as perceptual ability. More specifically, performance on the EFT has been shown to be indicative of intellectual ability to overcome an embedding context (Elkind, Koegler, \& Go, 1963; Goodenough \& Karp, 1961; Witkin, 1960a, 1960b; Witkin, Dyk, Faterson, Goodenough, \& Karp, 1962; Witkin et al., 1971; H. H. Young, 1959). Although Lee and Pollack (1978) found all of their subjects, regardless of age, to approach the problems with essentially the same cognitive strategies, they did find age differences in the length of time taken to solve the problems and the number of problems solved. Lee and Pollack interpreted the discrepancy between the qualitative data (i.e., the type of strategies employed) and the quantitative data (i.e., the time scores and the number correct) to intimate that the decline with age in problem solving ability could be due to an increase in perceptual field dependence (FD) involving figure-ground segregation rather than to an impairment in higher order cognitive processes. According to these investigators, the older subjects were possibly hindered in their performance by a deficit in some

This research was supported, in part, by a grant from the National Institute of Aging, Department of Health, Education, and Welfare, Grant AG-00297. Requests for reprints should be sent to Jo Ann Lee or Robert H. Pollack, Department of Psychology, University of Georgia, Athens, Georgia 30602. lower order perceptual process. Lee and Pollack based their hypothesis on Werner's (1957) theory of a hierarchy of functions constituting mental functioning.

The present study was conducted to investigate the importance of other perceptual factors in problem solving situations that measure perceptual FD but are not concerned directly with figure-ground segregation. Lee and Pollack's (1978) results with the EFT manifested a marked decline in performance on the quantitative measures between the 40- and 50-year-old groups. The present study was predicated on the thesis that additional results consistent with Lee and Pollack's, but obtained using perceptual tests that do not require higher order processes, would corroborate the hypothesis that a general perceptual deficit rather than cognitive factors produces an age-related decline in certain problem solving tasks. Failure to obtain similar results could indicate that the perceptual deficit is limited to figure-ground manipulation.

\section{METHOD}

\section{Subjects}

The sample consisted of 12 white middle-class females from each of the following three decade-age groups: $40 \mathrm{~s}, 50 \mathrm{~s}$, and $60 \mathrm{~s}$. This resulted in a total of 36 subjects, all of whom were volunteers from Athens, Georgia, and surrounding communities. All subjects had at least 20/33 corrected or uncorrected near and far vision as determined by the Master Orthorater. All subjects were moderately to well educated, healthy, and relatively active members of the community. Several of the subjects in the present study had also participated in Lee and Pollack's (1978) study.

\section{Procedure}

All subjects completed the following tests individually and without time limits. All three tests were administered during one session; there was an interval of approximately 2 min separating the tests.

The rod-and-frame test (RFT). The portable RFT (Oltman, 1968) was administered, with moderate modifications of the standard procedures. The standard number of trials, order of position of rod and frame, and the degree of tilt of rod and frame were maintained. Eight trials were given, with rod and frame initially tilted $28 \mathrm{deg}$, and the sequences of tilt direction for rod and frame were ( $\mathrm{L}=$ left, $\mathrm{R}=$ right) $L L R R L L R R$ and LRRLLRRL, respectively. The only alteration in procedure was 
how the subject adjusted the rod to what she perceived to be the objective vertical. Lasry and Dyne (1974) found that the greater the number of rod adjustments made, the less influence the frame exerted as an embedding context. The influence of the frame as an embedding context was maximized when only few adjustments were allowed. To maximize the effect of the frame in the present study, the subjects were instructed to make only one continuous slow movement of the rod. They were allowed to move the rod in only one direction until they attained what they perceived to be the objective vertical. The score for the test was the sum of the absolute deviations from the objective vertical over the eight trials given.

Ambiguous figures. Two series of ambiguous figures were administered to the subjects: the cat-dog (CD) series and the tree-house (TH) series. These two series were separated by $2 \mathrm{~min}$.

The CD series was similar if not identical to the CD series used by Botwinick (1962) and Korchin and Basowitz (1956). The series consisted of 13 photographs of drawings. The first is clearly a cat, and the last is clearly a dog. The intervening pictures represent gradual transformations of the cat to the dog. The drawings are approximately $4.5 \mathrm{in}$. wide and $3.25 \mathrm{in}$. high at the longest dimensions. They are drawn in black ink on white cards approximately 8 in. square.

The TH series was created by the first author. The format of the series is basically the same as that of the CD series, except that the subjects of the photographs are trees and houses. The dimensions of the TH figures are $3.25 \mathrm{in}$. wide and $4.5 \mathrm{in}$. high. These figures, too, were black on white cards.

The order in which the series were administered was counterbalanced. Half of the subjects in each age group received the CD series first; the other half received the TH first. Of the six persons in each age group who were administered the CD series first, three were presented the picture that was clearly a cat first. The other three were initially presented the picture most closely resembling a dog. This procedure was followed with the $\mathrm{TH}$ series also.

Subjects were instructed to indicate whether each picture was more like a cat (tree) or more like a dog (house). The number of the card in the sequence to which the subject changed her response was the score.

\section{RESULTS}

In analyzing the data collected on the three tests, the subjects were categorized three different ways. First, they were classified into the three decade-age groups. The grouping of subjects by age permitted direct comparison with Lee and Pollack's (1978) results, since they categorized their subjects by age. However, chronological age is a somewhat arbitrary standard of classification. Individual differences are not accounted for; persons age at different rates in many different aspects. Therefore, the subjects were regrouped according to menopausal status, that is, according to whether they were pre- or postmenopausal. Third, those subjects whose hormonal levels were maintained either naturally or artificially were compared with those whose normal hormonal levels had been interrupted and had not been sustained. A multivariate analysis of variance revealed no significant differences among the three age groups in their performances on the three tests (i.e., the RFT, CD series and TH series). No significant differences were found using the Hotelling-Lawley trace $[F(6,60)=.90$, $\mathrm{p}<.50]$, Pillai's trace $[\mathrm{F}(6,64)=.88, \mathrm{p}<.52]$, Wilk's criterion $[\mathrm{F}(6,62)=.89, \mathrm{p}<.51]$, or Roy's maximum root criterion $[\mathrm{F}(2,33)=2.95]$ as the test statistic. Table 1 contains the mean scores for each of the age groups for each of the administered tests.

Furthermore, a Hottelling's $\mathrm{T}^{2}$ indicated no significant differences between the premenopausal and the postmenopausal groups $[\mathrm{F}(3,32)=1.54, \mathrm{p}<.22]$. Table 2 contains the mean scores on each of the administered tests for the two groups. Nor did Hotelling's $\mathrm{T}^{2}$ reveal any significant differences in the third comparison $[F(3,32)$ $=.73, \mathrm{p}<.54]$. Table 3 contains the mean scores on each of the administered tests for the two groups. Hormonal level did not appear to be a significant factor affecting performance on the three tests administered.

In order to discern linear relationships existing among the variables, Pearson product-moment correlations were computed. Age was not significantly correlated with performance on any of the tests. All of the tests were significantly correlated with performance on any of the tests. All of the tests were significantly correlated $(p<.05)$ with each other. However, both the CD and the TH series were negatively correlated with the RFT. That is, a person assessed as being more field dependent on the RFT was less field dependent according to the ambiguous figures tests.

Table 1

Mean Scores for the Tree-House (TH), Cat-Dog (CD), and Rod-and-Frame (RFT) Tests for Given Age Groups

\begin{tabular}{cccc}
\hline $\begin{array}{c}\text { Decade-Age } \\
\text { Group }\end{array}$ & TH & CD & $\begin{array}{c}\text { RFT } \\
\text { (Degrees) }\end{array}$ \\
\hline $40 \mathrm{~s}$ & 8.08 & 7.17 & 47.79 \\
$50 \mathrm{~s}$ & 6.92 & 6.58 & 66.68 \\
$60 \mathrm{~s}$ & 7.0 & 6.58 & 67.17 \\
\hline
\end{tabular}

Table 2

Mean Scores for the Tree-House (TH), Cat-Dog (CD), and Rod-and-Frame (RFT) Tests for Pre- and Postmenopausal Subjects

\begin{tabular}{lcccc}
\hline & & & & RFT \\
& N & TH & CD & (Degrees) \\
\hline Premenopausal & 14 & 7.78 & 6.71 & 50.74 \\
Postmenopausal & 22 & 7.05 & 6.82 & 66.78 \\
\hline
\end{tabular}

Table 3

Mean Scores for the Tree-House (TH), Cat-Dog (CD), and Rod-and-Frame (RFT) Tests for "Hormonal" and "Nonhormonal" Groups

\begin{tabular}{lcccc}
\hline & N & TH & CD & $\begin{array}{c}\text { RFT } \\
\text { (Degrees) }\end{array}$ \\
\hline Hormonal & 18 & 7.61 & 6.56 & 59.85 \\
Nonhormonal & 18 & 7.06 & 7.0 & 61.23 \\
\hline
\end{tabular}

Note-The hormonal group includes participants whose hormonal levels were maintained either naturally or artificially. The nonhormonal group includes participants whose normal hormonal levels had been interrupted and had not been sustained. 


\section{DISCUSSION}

The data of the present experiment do not show the pattern obtained in Lee and Pollack's (1978) earlier study. Contrary to what was found by these researchers, no marked break between the performance of the 40- and 50-year-old women was evidenced in the present study. Moreover, neither menopausal status nor hormonal level was manifest as a determining factor upon which level of performance is contingent.

The inconsistency between the data of the two studies could be attributed to the fact that the EFT and the RFT do not measure precisely the same perceptual function. Several (specifically, 13 of 36) of the persons participating in the present study had also participated in Lee and Pollack's (1978) study. If the EFT and RFT do measure the same construct, then the results obtained in the present study should be compatible with those of Lee and Pollack's earlier study. Moreover, other researchers (Bergman \& Engelbrektson, 1973; Baker, Mishara, \& Kostin, Note 1) have espoused the argument that FD is not a unitary trait.

The present authors posit that the EFT is distinct from the RFT in that the forner taps the ability to segregate a figure embedded in a ground, while the latter is concerned with the major sensorimotor dimensions of space (vertical and horizontal). Taking the results from Lee and Pollack's (1978) study together with the results of the present study, it appears as though the decline in the performance of elderly females is due to a perceptual-cognitive problem, rather than to a body-perception problem.

The thesis here is that there are different levels of operation, ranging from purely sensorimotor to higher order cognitive processes. Moreover, it is maintained that malfunctions extant at the lower and/or middle levels of functioning have the potential of impeding higher level functioning. What is needed is another study utilizing tasks, specifically requiring perceptual figure ground manipulation. From the present study, it appears that there is no significant decline in performance from middle age to early old age in the ability to estimate the true vertical.

The significant negative correlation between the ambiguous figures series and the RFT is interpreted as indicating that these two types of tests do not tap the same underlying ability. The CD series was originally used by Frenkel-Brunswick (1949) to investigate the concept of "tolerance of perceptual ambiguity" and has since been employed as a measure of personality organization (Korchin \& Basowitz, 1956) and perceptual modification (Botwinick, 1962). In other words, the CD series assesses a personality factor. Given this definition of the $C D$ series and the results obtained, there appears to be no significant difference between the personality structures (as measured by the ambiguous figures series) of the groups in the present study. The ability to manipulate figure-ground relationships voluntarily seem to be a specific perceptual component of the FD dimension that requires further investigation.

\section{REFERENCE NOTE}

1. Baker, A. H., Mishara, B. L., \& Kostin, I. W. Field independence and stimulation seeking re-visited: Methodological comment and new data. Paper presented at the meeting of the Eastern Psychological Association, Washington, D.C., March 1978.

\section{REFERENCES}

Arenberg, D. Cognition and aging. In C. Eisdorfer \& M. P. Lawton (Eds.), The psychology of adult development and aging. Washington, D. C: American Psychological Association, 1973.

Axelrod, S., \& Cohen, L. D. Senescence and embedded figure performance in vision and touch. Perceptual and Motor Skills, 1961, 12, 283-288.

Baltes, P. B., \& Labouvie, G. V. Adult development of intellectual performance: Description, explanation, modifica- tion. In C. Eisdorfer \& M. P. Lawton (Eds.), The psychology of adult development and aging. Washington, D.C: American Psychological Association, 1973.

Basowitz, H., \& Korchin, S. J. Age differences in the perception of closure. Journal of Abnormal and Social Psychology, 1957, 54, 93-97.

Bergman, H., \& Engelbrektson, K. An examination of factor structure of rod-and-frame test and embedded-figure test. Perceptual and Motor Skills, 1973, 37, 939-947.

Botwinick, J. A research note on the problem of perceptual modification in relation to age. Journal of Gerontology, 1962, 17, 190-192.

Clay, H. M. Changes in performance with age in similar tasks of varying complexity. British Journal of Psychology, 1954, 45, 7-13.

Elkind, D., Koegler, R. R., \& Go, E. Field independence and concept formation. Perceptual and Motor Skills, 1963, 17, 383386.

Frenkel-Brunswick, E. Intolerance of ambiguity as an emotional and perceptual personality variable. Journal of Personality, $1949,18,108-143$.

Friend, C. M., \& Zubeck, J. P. The effects of age on critical thinking ability. Journal of Gerontology, 1958, 13, 407-413.

Goodenough, D. R., \& KARP, S. A. Field independence and intellectual functioning. Journal of Abnormal and Social Psychology, 1961, 63, 241-246.

Jerome, E. A. Decay of heuristic processes in the aged. In C. Tibbitts \& W. Donahue (Eds.), Social and psychological aspects of aging. New York: Columbia University Press, 1962.

Korchin, S. J., \& Basowitz, H. The judgment of ambiguous stimuli as an index of cognitive functioning in aging. Journal of Personality, 1956, 25, 81-95.

LASRY, J., \& Dyne, L. Administration procedures and correlations between Witkin's test of field dependence. Perceptual and Motor Skills, 1974, 38, 216-218.

LeE, J. A., \& Pollack, R. H. The effects of age on perceptual problem-solving strategies. Experimental Aging Research, 1978, 4, 37-54.

Oltman, P. K. A portable rod-and-frame apparatus. Perceptual and Motor Skills, 1968, 26, 503-506.

Welford, A. T. Ageing and human skill. London: Oxford University Press, 1958.

Welford, A. T. Age and skill: Motor, intellectual and social. In A. T. Welford \& J. E. Birren (Eds.), Interdisciplinary topics in gerontology (Vol. 4). Basel, Switzerland: Karger, 1969.

WERNER, H. Comparative psychology of mental development. (rev. ed.) New York: International Universities Press, 1957.

Wiersma, W., \& Klausmeier, H. J. The effects of age upon speed of concept attainment. Journal of Gerontology, 1965, 20, 394-400.

Witkin, H. A. Embedded figures and personality: A reply. Perceptual and Motor Skills, 1960, 11, 15-20. (a)

Witkin, H. A. The problem of individuality in development. In B. Kaplan \& S. Wagner (Eds.), Perspectives in psychological theory. New York: International Universities Press, 1960. (b)

Witkin, H. A., Dyk, R. B., Faterson, H. F., Goodenough, D. R., \& KARP, S. A. Psychological differentiation. New York: Wiley, 1962.

Witkin, H. A., Oltman, P. K., Raskin, E., \& Karp, S. A. A manual for the embedded figures tests. Palo Alto, Calif: Consulting Psychologists Press, 1971.

YounG, H. H. A test of Witkin's field-dependence hypothesis. Journal of Abnormal and Social Psychology, 1959, 59, 188192.

Young, M. L. Problem-solving performance in two age groups. Journal of Gerontology, 1966, 21, 505-509.

Young, M. L. Age and sex differences in problem solving. Journal of Gerontology, 1971, 26, 330-336.

(Received for publication January 16, 1980.) 